\title{
TRANSFORMING SEISMIC DATA INTO LATERAL SONIC PROPERTIES USING ARTIFICIAL NEURAL NETWORK: A CASE STUDY OF REAL DATA SET
}

\author{
Abdul Haris ${ }^{1 *}$, Befriko S. Murdianto ${ }^{1}$, Rochmad Sutattyo $^{2}$, Agus Riyanto $^{2}$ \\ ${ }^{1}$ Master Program in Reservoir Geophysics, Faculty of Mathematics and Natural Sciences, Universitas \\ Indonesia, Kampus UI Depok, Depok 16424, Indonesia \\ ${ }^{2}$ Geophysics Study Program, Faculty of Mathematics and Natural Sciences, Universitas Indonesia, \\ Kampus UI Depok, Depok 16424, Indonesia
}

(Received: September 2017 / Revised: January 2018 / Accepted: March 2018)

\begin{abstract}
Transforming seismic data into lateral sonic log properties was carried out successfully using the artificial neural network (ANN). This work is related to a detailed investigation of reservoir properties that requires complete data. The objective of this paper is to build a geological model that has vertical and lateral distribution representing the framework of geological change of sonic log properties. However, detailed well log data analysis only provides information of vertical distribution, therefore effective application of seismic data is required to construct a spatial distribution model that represents the lateral sonic log properties away from a well. This paper presents a strategy for transforming seismic data into pseudo-sonic log data by using ANN approaches rather than a simple approach of empirical relationship. The ANN approach defines a specific function that correlates a series of attributes generated from seismic data, such as amplitude envelope, instantaneous frequency, instantaneous phase, and acoustic impedance by a training mechanism based on the sonic log data as a target parameter. The probabilistic neural network (PNN) as one ANN algorithm is applied to transform seismic attributes into a lateral sonic log. An example of an ANN approach using a real data set from the Indonesian field was presented. The pseudo-sonic log shows a good agreement with the real sonic log data, which is represented with a correlation coefficient of 0.91 . Further, the seismic line data was successfully transformed into the pseudo lateral sonic log data that covers the whole seismic line.
\end{abstract}

Keywords: Artificial neural network (ANN); Pseudo sonic log; Seismic attributes

\section{INTRODUCTION}

Reservoir characterization requires many types of data utilization, both of geoscience and engineering data. Two of the most commonly used datasets are seismic and wireline well log data (Itoa et al., 2017). The integration of this data is not an easy task since they have different characteristics and approaches. The three-dimensional (3D) seismic data is sampled in arrival time domain, covering a large area with evenly spaced bins in the spatial directions and limited band resolution for the deepest target, whereas wireline data are sampled in depth, only available at the well locations and having a higher resolution in-depth domain. The vertical resolution of seismic data is typically on the order of tens of time; on the other hand, the vertical resolution of wireline log data is on the order of tenths of meters (Brown, 1999). The strengths and weaknesses of seismic and wireline log data make combinations of those interpretations the

*Corresponding author's email: aharis@sci.ui.ac.id, Tel. +62-21-7270013, Fax. +62-21-7270012

Permalink/DOI: https://dx.doi.org/10.14716/ijtech.v9i3.751 
most effective inputs for predicting the lateral distribution of a pay zone or hydrocarbon reservoir (Haris et al., 2017a).

The application of ANN has been broadly used in reservoir properties interpretation. Balch et al. (1999) have projected the correlation between selected attributes, such as porosity, water saturation and net pay thickness using ANN application. The others (Chawathe et al., 1997) used ANN to predict the gamma ray by transforming seismic attributes that include amplitude, phase, frequency, reflection strength and quadrature. Haravinthan et al. (2011) proposed the same method for predicting the synthetic well in a new location by applying mathematical dependency between seismic travel time and wireline log data from neighboring wells. Thus, this approach has become the common method for determining an unknown variable within the available ones.

A common approach to integrate the two datasets is to use forward and inverse modeling. Forward modeling is simply generating the seismic response from the petrophysical properties obtained from well log data, while inverse modeling is trying to predict the well log data using the seismic data, which was well known as seismic inversion (Lindseth, 1979; Oldenburg et al, 1983). This paper applies a different approach, which defines the specific function from the available seismic attributes. The log properties were predicted from a series of seismic attributes trained using ANN approach (Eskandari et al., 2004). A series of training sessions are carried out over intervals where both seismic and well data exist. Further, the system was trained to predict well log properties using a standard ANN algorithm into a seismic feature laterally (Eskandari et al., 2004; Haris, et al., 2017b).

\section{ARTIFICIAL NEURAL NETWORK}

The simple way to transform the targeted parameter can be carried out directly by using a linear relationship. Nevertheless, this approach often simplifies the heterogeneity of the variable that controls to the transformed parameter (Locascio \& Atri, 2011). Therefore, this approach is not suitable to transform seismic data into a well log that has limited lateral resolution. The ANN approach offers a more realistic strategy to transform seismic data into well log data by considering the lateral characteristics of seismic data.

Neural network computational systems are adopted from the biological neural network in the human brain. The brain has a number of dendrites, which input to the nucleus as neural processors then transmit the output information within the axon. The computational logic of a neural network has the same structure. The various given data are used to predict new unknown data. In geoscience, seismic attributes (amplitude, phase, and frequency) or wireline data (gamma ray and sonic) are inputted into a formulation system to predict the new parameter. The results must have good correlation with existing data, and the best correlation of predicted results defines the formulation steps that are used for next calculations. This work used seismic attributes for determining the sonic log properties mapped seismically, which is validated by real sonic log data (Taner et al., 1994).

There are various existing formulation types of neural network. The type of neural network used in this approach is the multilayer feed-forward neural network (MLFN), which was described by Liu and Liu (1998). This type of neural network algorithm covers an input layer, an output layer, and one or more hidden layers. However, other neural network methods, such as the probabilistic neural network (PNN) (Hampson et al., 2000) could be used as an alternative. The choice of MLFN is based on the fact that this type of neural network is a supervised neural network (multilayer perceptron) that learns through a process called backpropagation. Backpropagation is a form of gradient descent that is suitable for our problem. Here, the network is supplied with a series of input and corresponding correct (wanted) output. 
The network then tries to set its own parameters until it can approximate an unknown function that can associate input data with the corresponding wanted output (Hampson et al., 2000). In this paper, the ANN was used to transform the seismic data into the pseudo-sonic log properties in lateral distribution.

\section{ANN APPLICATION TO REAL SEISMIC DATASETS}

The ANN application to the real seismic dataset is intended to transform the seismic dataset into the lateral distribution of sonic log properties across an oil reservoir in Indonesia. The objective of the study was to map the distribution of hydrocarbon-bearing sand using seismic data and wireline $\log$ as control of vertical resolution. The oil-bearing reservoir is a lowvelocity zone anomaly based on petrophysical studies. The seismic dataset consists of an inline extracted from 3D seismic data and well log data from two wells (S-1 and X-1) that intersect the seismic line. Figure 1 shows the real seismic line that passes through the two wells' data. The well log data consists of neutron density, gamma ray, resistivity, and sonic logs. The analysis of these two wells' log data is shown in Figure 2 (well S-1) and Figure 3 (well X-1). Figure 2 shows gamma ray, resistivity and sonic log for well S-1 with an interesting zone within the blue lines just above 6,000 feet with a thickness of about 200 feet, which is interpreted as hydrocarbon-bearing sand. Figure 3 shows gamma ray, resistivity and sonic log for well X-1 with an interesting zone within the blue lines in the same depth of well S-1, which is interpreted as hydrocarbon-bearing sand. This oil reservoir is characterized by the number of log data, such as low gamma ray (left panel), high resistivity (middle panel), and low velocity or high sonic (right panel).

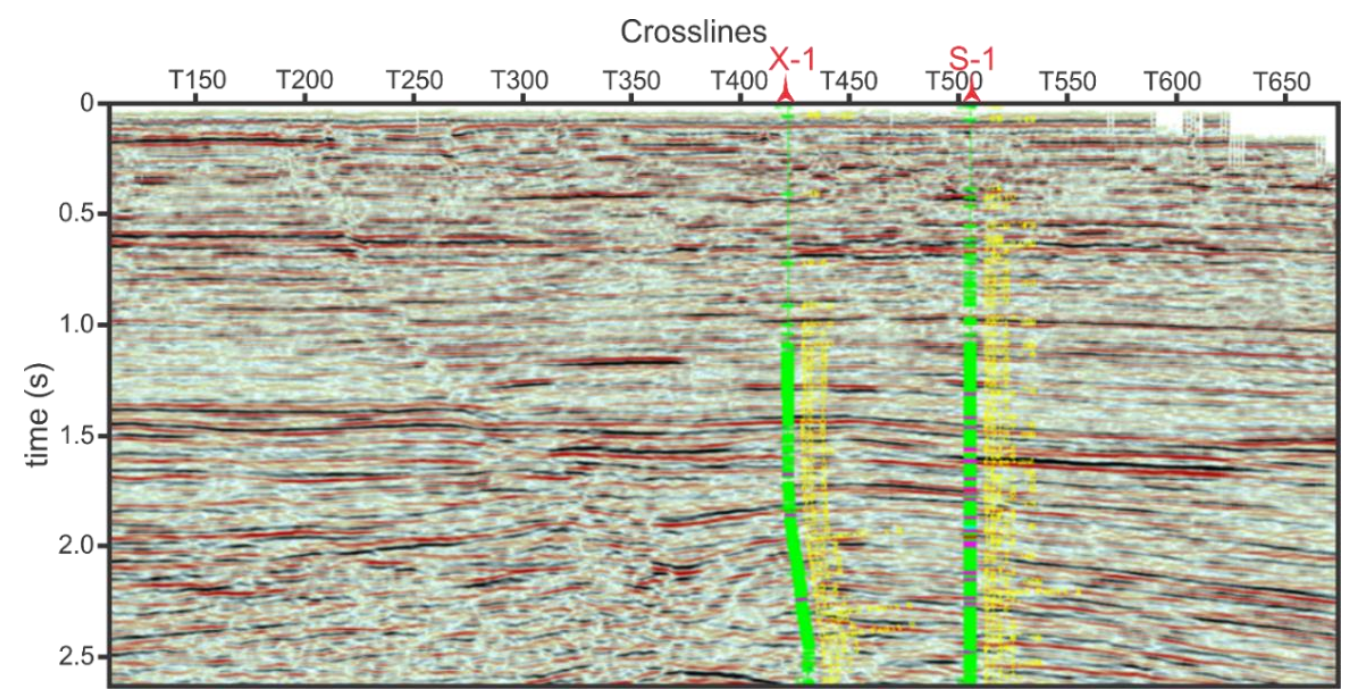

Figure 1 The inline seismic data extracted from a 3D seismic cube with well locations (X-1 and S-1) superimposed. The net pay is placed between $1.5-2.0 \mathrm{~s}$, which is indicated by strong amplitude responses

Referring to these two wells' log data, we only know the detailed subsurface information in the vertical direction. There is no detailed subsurface information in lateral distribution. The lateral sand distribution can only be detected from sonic logs if there are laterally distributed wells with sonic logs covering the entire area of interest (Lindseth, 1979). This is usually not the case, therefore using seismic data to extrapolate the sonic velocity log away from available well data is required. The ANN approach would be used to generate a sonic log section that is consistent with the log information at the well locations and constrained by seismic data to enable us to predict the lateral distribution of the oil-bearing sand reservoir. 

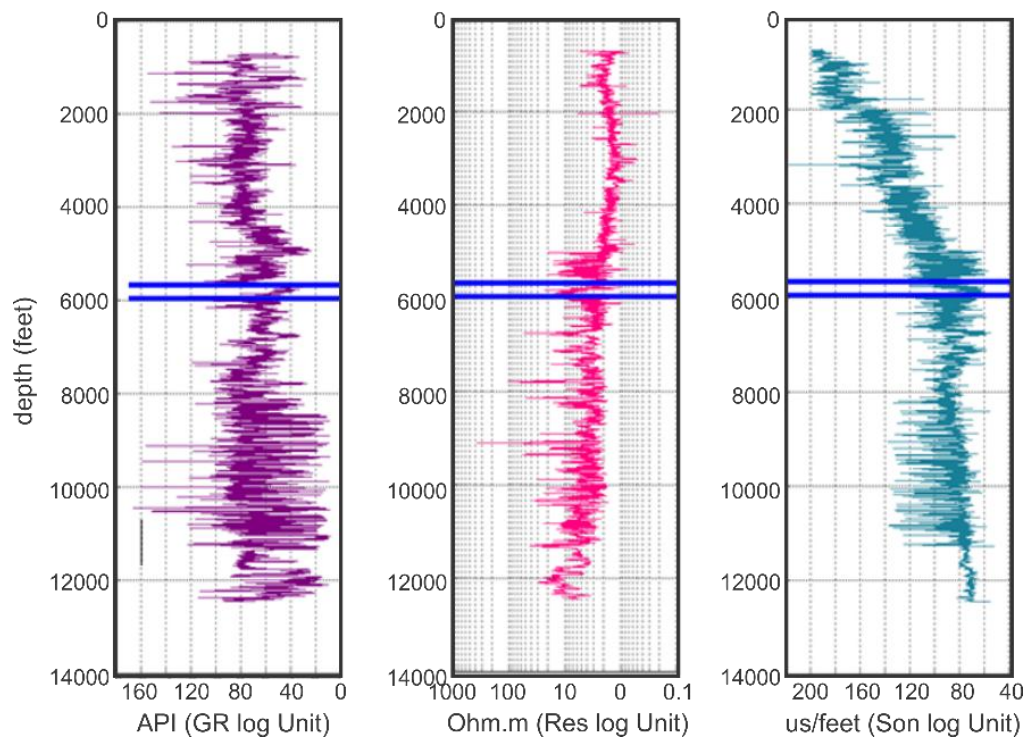

Figure 2 Well log data analysis of well S-1. The left panel is a gamma-ray log, the middle panel is resistivity log, and right panel is a sonic log
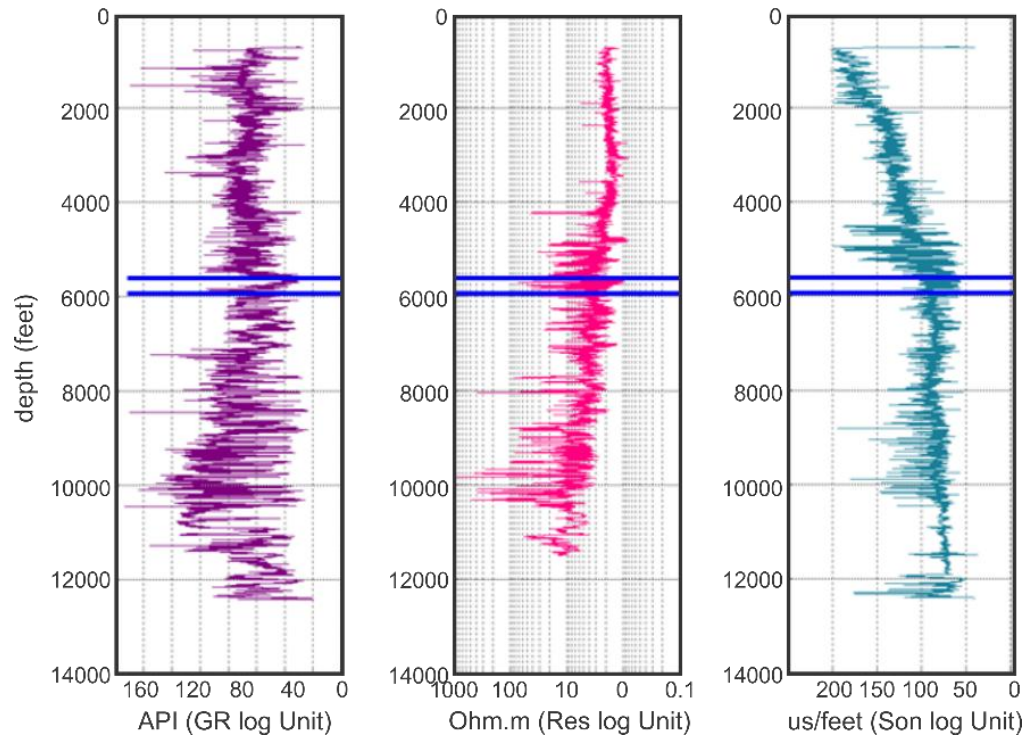

Figure 3 The analysis of well X-1. The left panel is a gamma-ray log, the middle panel is resistivity log, and right panel is a sonic log

The seismic attributes, which are a derivative function of seismic data, are then generated from the seismic data as inputs to the neural network algorithm. The generated seismic attributes include amplitude envelope, instantaneous phase, instantaneous frequency and acoustic impedance. Acoustic impedance trends from the two wells are used to provide the neural network with low-frequency information to train the network appropriately to get the best result of the lateral distribution. If this low-frequency trend is not provided to the neural network, it fails to predict the expected output. Figure 4 shows the predicted sonic log of well S-1 (left), well X-1 (right) and its cross-validation without low-frequency information in the training. The predicted sonic log from ANN is shown in red, while the real sonic log data is shown in blue.

Acoustic impedance was generated using the band-limited algorithm as described in Ferguson and Margrave (1996). The attributes generated from the seismic data are trained on one of the wells (S-1) using Levenberg-Marquardt optimization algorithm, which iteratively adjusts 
weights and biases to minimize mean-squared errors. Once the training was completed, the verification was then applied to the other well that was not used in the training process $(\mathrm{X}-1)$. This process is called cross-validation.
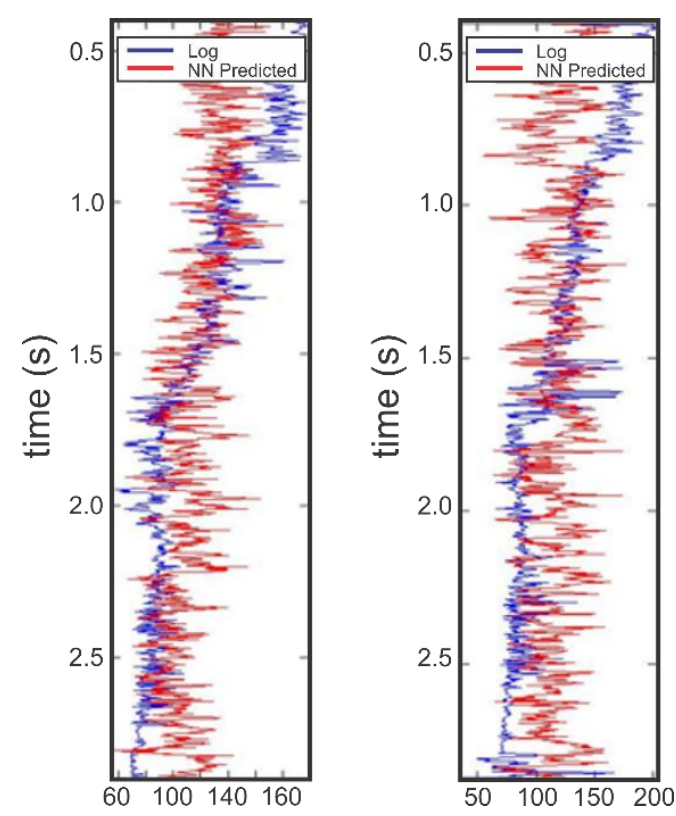

Figure 4 Predicted sonic log of well S-1 (left), well X-1 (right), and its cross-validation without lowfrequency information in the training. The predicted sonic log from ANN is shown in red, while the real sonic log data is shown in blue
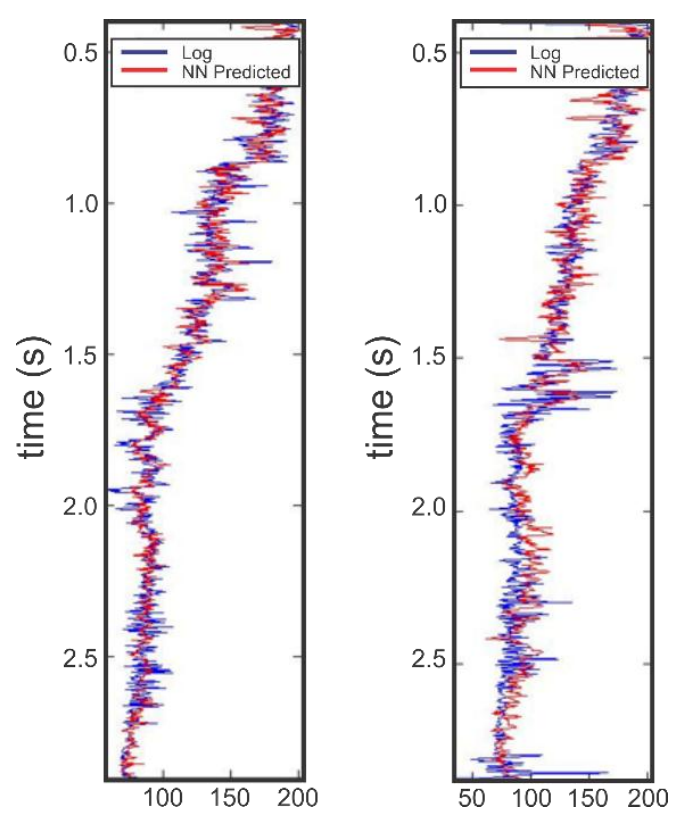

Figure 5 Predicted sonic log of well S-1 (left), well X-1 (right), and its cross-validation with lowfrequency information in the training obtained from acoustic impedance (compared to Figure 4). The predicted sonic log from ANN is shown in red, while the real sonic log data is shown in blue

Figure 5 shows the training result with the selected attributes for input to the neural network of well S-1 (left) and its cross-validation on well X-1 (right). The results show that the neural network has predicted the sonic log reasonably compared to real log data, which is indicated with a correlation coefficient of 0.98 . 


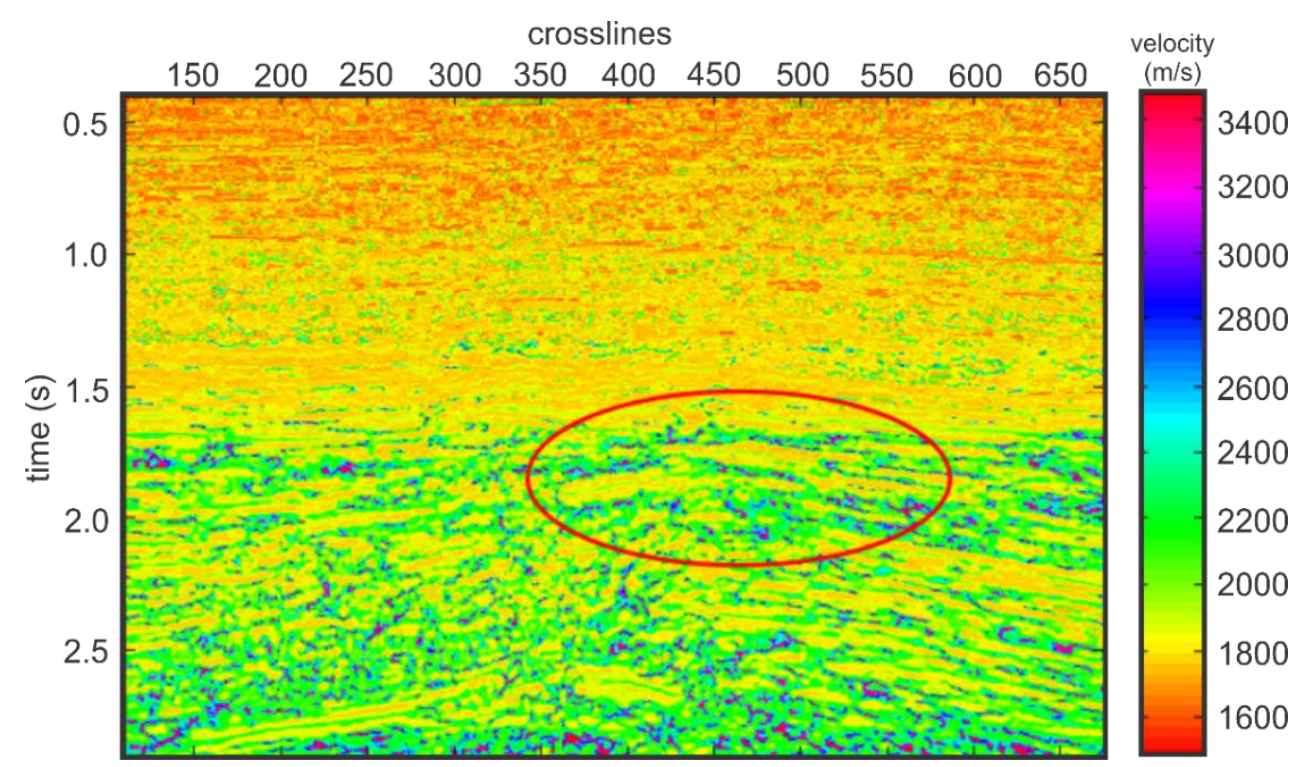

Figure 6 Sonic log section generated on the whole line using the result from ANN training on well location. Note the low-velocity distribution below $1.5 \mathrm{~s}$ (circled area), which is consistent with the well $\log$ data

The training results also have a good correlation to another well that is not used for the training with a correlation coefficient of 0.91 . The prediction was then carried out to the entire seismic section, generating a laterally distributed sonic log prediction for the whole seismic line. Figure 6 shows a sonic log section generated on the whole section using the result from ANN training on well location. The section shows the low-velocity distribution, which is consistent with the well $\log$ data, particularly under $1.5 \mathrm{~s}$ indicated by a circled area. An interesting result is observed between 1.5 and 2.0s; here there is a low-velocity zone consistent with the zone of interest from the well log data. This low-velocity zone is interpreted as sand distributed within the area that has pay zone according to well interpretation.

\section{CONCLUSION}

The lateral sonic log properties were successfully generated from a series of seismic attributes by using artificial ANN. This work is related to a detailed investigation of reservoir properties that require complete data. The detailed lateral sonic log property that covers the whole seismic line provides useful information for reservoir characterization, which represents the lateral heterogeneity. The predicted sonic log properties are highly dependent on the input data used for network training. A set of input data that can generate optimum results should be used. Finally, the outputs have shown how selecting the optimum input data for training can increase the accuracy of the prediction significantly. An interesting result is observed between 1.5 and $2.0 \mathrm{~s}$; here there is a low-velocity zone consistent with the zone of interest from the well $\log$ data. This low-velocity zone is interpreted as sand distributed within the area that has pay zone according to well interpretation.

\section{ACKNOWLEDGEMENT}

The authors would like to thank Basic Research Excellent Grant for University from Kemenristekdikti with the contract number: 360/UN2.R3.1/HKP.05.00/2018 for supporting this fund's research. Moreover, the authors hope that this paper might be useful for scientific developments, especially in computational geoscience. 


\section{REFERENCES}

Balch, R.S., Stubbs, B.S., Weiss, W.W., Wo, S., 1999. Using Artificial Intelligence to Correlate Multiple Seismic Attributes to Reservoir Properties. In: SPE Annual Technical Conference and Exhibition Proceedings, Oct. 3-6, Houston, Texas, pp. SPE 56733

Brown, A.R., 1999. Interpretation of Three-dimensional Seismic Data. $5^{\text {th }}$ Edition. AAPG Memoir 42, Tulsa, Oklahoma, pp. 514

Chawathe, A., Ouenes, A., Weiss, W.W., 1997. Interwell Property Mapping using Crosswell Seismic Attributes. In: SPE Annual Technical Conference and Exhibition Proceedings, Oct. 5-8, San Antonio, Texas, pp. SPE 38747

Eskandari, H., Rezaee, M.R., Mohammadnia, M., 2004. Application of Multiple Regression and Artificial Neural Network Techniques to Predict Shear Wave Velocity from Wireline Log Data for a Carbonate Reservoir South-West Iran. CSEG recorder, pp. 42-48

Ferguson, R.J., Margrave, G.F., 1996. A Simple Algorithm for Bandlimited Impedance Inversion. CREWES Research Report, 8, pp. 1-10

Hampson, D.P., Schuelke, J.S., Quirein, J.A., 2000. Use of Multiattribute Transforms to Predict Log Properties from Seismic Data. Geophysics, Volume 66(1), pp. 220-236

Haravinthan, A, Ayob, M.R., Saleh, S., Japper-Jaafar, A., 2011. A Review on Predicting of Abnormal Geo-pressure via Seismic Travel Time and Wire Line Log Correlation Modelling using Neural Network. International Journal of Information and Electrical Engineering, Volume 1(3), pp. 195-199

Haris, A., Nafian, M., Riyanto, A., 2017a. Delineating Chalk Sand Distribution of Ekofisk Formation using Probabilistic Neural Network (PNN) and Stepwise Regression (SWR): Case study Danish North Sea field. In: AIP Conference Proceedings, Volume 1862(1), p. 030170

Haris, A., Sitorus, R.J., Riyanto, A., 2017b. Pore pressure prediction using probabilistic neural network: case study of South Sumatra Basin. In: IOP Conference Series: Earth and Environmental Science, Volume 62(1), p. 012021

Itoa, T., Nakajimaa, T., Xuea, Z., 2017. Geological Reservoir Characterization and Modelling of a $\mathrm{CO}_{2}$ Storage Aquifer: A Case Study of the Nagaoka Site, Japan. Energy Procedia, Volume 114, pp. 2792-2798

Lindseth, R.O., 1979. Synthetic Sonic Logs - A Process for Stratigraphic Interpretation. Geophysics, Volume 44, pp. 3-26

Liu, Z., Liu, J., 1998. Seismic-controlled Nonlinear Extrapolation of Well Parameters using Neural Networks. Geophysics, Volume 63, pp. 2035-2041

Locascio, J.J., Atri, A., 2011. An Overview of Longitudinal Data Analysis Methods for Neurological Research. Dementia and Geriatric Cognitive Disorders Extra, Volume 1(1), pp. 330-357

Oldenburg, D.W., Scheuer, T., Levy, S., 1983. Recovery of the Acoustic Impedance from Reflection Seismogram. Geophysics, Volume 48, pp. 1318-1337

Taner, M.T., Schuelke, J.S., O'Doherty, R., Baysal, E., 1994. Seismic Attributes Revisited. In: SEG Technical Program Expanded Abstracts, pp. 1104-1106 